\title{
For people and planet
}

\author{
The emerging field of geohealth links human well-being and ecosystem health. A deeper understanding of \\ these linkages can help society mitigate the health costs of economic growth before they become crises.
}

In December 1952, unfavourable weather conditions combined with air pollution and resulted in a killer fog in London that led to thousands of deaths ${ }^{1}$. Incidences such as this one focus the attention to how we are transforming the planet, and how that transformation affects human health. The Great Smog of London brought the problem of air pollution into the public eye. Work that followed in the 1960s and 1970s firmly established the toxicity of lead, which by that point was emitted copiously to the environment. Eventually concerns over public health led to the ban of lead as a gasoline additive in all but a handful of countries, and to restrictions on emissions from smelting operations.

Often society only acts in response to catastrophe. China and India are currently grappling with severely compromised urban air quality that is peeling years off their citizens' lives. Development in these countries has raised millions out of poverty, but air pollution now kills an estimated 2.2 million people each year $^{2}$. These health crises are an entirely predictable consequence of powergeneration choices and the growth of the transport sector starting in the 1990s. The science has been clear for at least as long. The lessons that were learned in London and Los Angeles could have been applied - but at the cost of implementing pollution-control technologies and policies. When governments develop plans for economic growth, their focus tends to be on development, not health. Only when faced with a crisis do health considerations take centre stage.

Europe and North America went through a period of heavy pollution a century or so ago. In the mid- and late-twentieth century, severe pollution triggered clean-air policies and increased environmental monitoring regions such as Europe and North America. Too often, observations of pollution start long after the transformation of the environment was under way. It was only in 2014 that India established its national air quality index and began routine air quality monitoring of some pollutants ${ }^{3}$. This was an important step, and provides the public with real-time information on air quality that could help to save lives. But in the preceding decades, direct measurements of

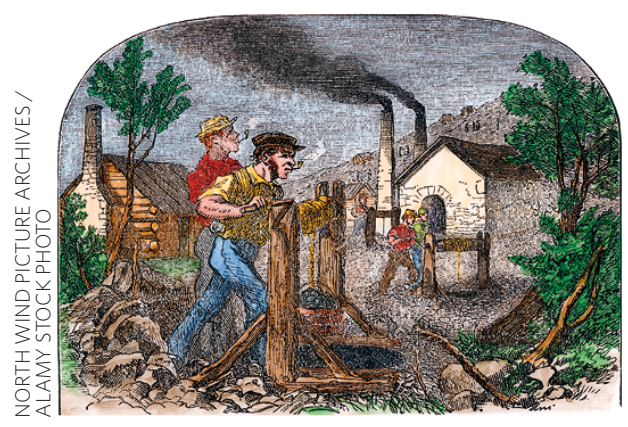

pollutant trajectories have substantial gaps. Since the health impacts of air pollution are the related to cumulative exposure, these gaps leave our understanding of the specific health risk poorly constrained.

Forensic efforts to uncover the historical pollution burden experienced by human populations have helped to close some gaps in our understanding of how, where and when humans polluted their environment. For example, sediments from a stormwater retention pond in New York track the usage of leaded gasoline as well as a decline in arsenic deposition after pollution control technologies were implemented at nearby coal-fired power plants ${ }^{4}$. Sediments from urban ponds in northwest England were used to reveal the rise of pollutant deposition from the beginning of the industrial revolution in the nineteenth century, to the decline in the wake of Clean Air Acts in the mid twentieth century ${ }^{5}$. These kinds of reconstructions could be used to inform our understanding of diseases with long latency times. The past is prelude for today's health outcomes.

Even further back in time, a hiatus in human activity left its mark as a brief environmental recovery. In a highresolution ice core that records atmospheric lead deposition in Europe over the past 2000 years, lead levels are found to be precipitously low from roughly 1349 to 1353, when the Black Death wiped out significant fractions of the population ${ }^{6}$. The findings suggest that what had been considered natural background concentrations were actually the result of mining and smelting operations. Lead in ice cores and sediments is a time-stamped record of human distribution of toxic metals in the environment.
The world has seen that choices based on narrow economic interests can result in profoundly negative public health impacts. Sometimes those impacts can be clearly anticipated: atmospheric and epidemiologic models have reached a level of maturity where the health impacts of bringing new coal-fired plants online can be quantified with reasonable confidence. The full implications of other environmental health impacts remain uncertain. For example, climate change is expected to expand the species ranges of numerous tropical infectious diseases to higher latitudes, but the degree of these range expansions and their health impacts remains murky. And there are almost certainly a category of unknown effects that have not been identified yet. Heavy metals, endocrine disruptors and other compounds were only discovered to adversely affect human health long after they had been routinely emitted to the environment. The emerging field of geohealth is looking to uncover such links between the health of the planet and its ecosystems, and the health of the people that live on it.

Governments have not always been able to protect their citizens even from known impacts. It is hard to know how well the world will be able to tackle the uncertain challenges inherent in the slow burn of climate change. Support of primary and applied research and monitoring of the environment are essential if we want to get ahead of the story, and take action before another catastrophic moment of human suffering comes about.

\footnotetext{
References

1. Wang, G. et al. Proc. Natl Acad. Sci. USA 113, 13630-13635 (2016).

2. State of Global Air: A Special Report on Global Exposure to Air Pollution and its Disease Burden (Health Effects Institute, 2017).

3. India launches air quality index to warn over dangerous pollution events. The Guardian (17 October 2014).

4. Graney, J. R. \& Eriksen, T. M. Appl. Geochem. 19, 1177-1188 (2004).

5. Power, A. L. \& Worsley, A. T. Environ Geochem. Health 31, 327-338 (2009).

6. More, A. F. et al. Geohealth http://dx.doi. org/10.1002/2017GH000064 (2017).
} 